\title{
Editorial
}

Gerontology

Published online: December 18, 2012

DOI: $10.1159 / 000345656$

\section{The Last Taboo}

Some years ago, at a conference on aging, chatting during a cruise on the Neva along the breathtaking silhouette of St. Petersburg, I stood at the guard rail next to a gerontologist from the UK. We had known each other for many years, and had formed one of the typical inner circle collegial acquaintances with interests in a similar field of scientific research. During our relaxed small talk on the boat, I happened to ask him how old he was and - to my surprise - received an indignant gaze and no response. In fact, this colleague avoided me for the rest of the conference, and this one-sided antipathy seems to linger even to this day. That was a new and unexpected experience for me, and I asked myself if this was due to a general cultural difference between the Central European and the Anglo-Saxon world. I myself grew up and was socialized in Austria where one learnt not to ask women about their age. However, inquiring about the age of a man is completely in order. Surprisingly, in a world where homosexuals are 'coming out', where people openly admit to having an alcohol problem, where the whole story of past and present living conditions is communicated to a plethora of 'friends' on Twitter and Facebook, in the era of Grey Panthers and Silver Agers, to 'confess' one's own age still seems to be the last taboo. In our world centered on the quest for eternal youth where most people in developed countries now get old in good health, and biological age often defies calendrial age, this fact is absurd. Not to stand by one's age will not make the inevitable agedependent physical and mental shortcomings go away. As a matter of fact, not answering to the innocent question on a person's age seems to signal that this person really does not accept the irrevocable rules of life. In contrast, we should look upon role models from art [1], science, politics and all other facets of society where old individuals often reached the peak of their creativity late in their lives, such as the painters Titian (Tiziano Vecello) and P. Picasso, the politicians K. Adenauer in Germany and W. Churchill in the UK, scientists from Galileo Galilei to the inventor of aspirin, F. Hofmann, as well as the current president of Italy, G. Napolitano, who acts as a competent authority in politically stormy times at the age of 87 .

If we accept our age as a fact of life, we will also develop sufficient self-confidence to treat inquiries about our age as part of our daily discussion culture. Incidentally, I am 73, run a successful research lab that is fully supported by competitive grants (www.autoimmunity. at), as well as a medical diagnostic lab (www.laborwick. com), and I enjoy the challenge of being Editor-in-Chief of Gerontology.

2012 was a good year for the Journal! Our impact factor rose significantly to 2.777 . (There is, of course, still room for further improvement!) Our acceptance rate for submitted papers fell to around $15 \%$ due to the increased influx of manuscripts and the shortage of space. In addition to selecting only the best Original Papers, we also solicited highly interesting Mini-Reviews and Viewpoint articles and have triggered lively debates. Occasionally, we also allowed for publication of papers of broad interest that did not fit into one of our classical sections [2]. The turnover time for manuscripts has once again been shortened to 18.2 days (2011: 21.5 days). However, here, too, we strive after further improvement, e.g. by applying an in-

\section{KARGER \\ Fax +4161306 1234 \\ E-Mail karger@karger.ch}

www.karger.com (c) 2012 S. Karger AG, Basel

0304-324X/13/0592-0097\$38.00/0

Accessible online at: www.karger.com/ger 
house triage system by the Editor-in-Chief and the Section Editors that is operative on the very day of receipt. This helps to avoid unnecessary delay in manuscript processing on one hand and gives the authors - should the decision be negative - the immediate chance to submit their work elsewhere.

I would like to thank all Section Editors, Members of the Editorial Board, all reviewers, contact persons at the Karger Publishing House and my secretariat for their help to make editing Gerontology such an interesting and rewarding task. This year, special thanks go to Günter Lepperdinger (Editor of the Regenerative Section) for taking care of incoming manuscripts during my travels, and to Christine Süss, who competently manages Geron- tology's Editorial Office ever since the beginning of my editorship.

Also, thanks to those members of the Editorial crew who rotate off their position at the end of 2012, for their generous donation of time and expertise. We welcome the new Section Editors and Members of the Editorial Board, and I am looking forward to a scientifically and personally fruitful cooperation in the years to come.

G. Wick, Innsbruck

References

1 Wagner M: Art and aging. Gerontology 2009;55:261-370.

2 Weksler ME, Weksler BB: The epidemic of distraction. Gerontology 2012;58:385-390. 